\title{
A Well-to-Wheel Hazard Analysis to Encourage the Use of LNG as an Alternative Fuel
}

\author{
Sarah Pfoser, Laura Simmer, and Oliver Schauer
}

\begin{abstract}
Liquefied Natural Gas (LNG) is increasingly used as alternative fuel for heavy-duty vehicles and vessels. However, the specific requirements for handling this cryogenic liquid are sometimes causing uncertainty. To encourage the application of LNG, a deliberate hazard analysis has been carried out in order to determine potential risks and illustrate protective measures. On this basis, required competences for personnel involved in LNG activities have been defined to facilitate safe operations in this industry. Empirical evidence has been gathered by means of online questionnaires and confirmed the relevance of the stated competences. The aim of the study is to raise awareness and knowledge about the safety concerns related to LNG in order to promote its use as an alternative fuel.
\end{abstract}

Index Terms-Alternative fuel, hazard analysis, liquefied natural gas, personnel competences.

\section{INTRODUCTION}

LNG is the liquefied form of natural gas cooled down to about minus $162^{\circ} \mathrm{C}$, depending on its exact composition. This kind of processing natural gas is accomplished because the volume of LNG in its liquid form is reduced 600 times and it is therefore ideally suited for the purpose of transport and storage. The described technology is already several decades old and well established; the first commercial liquefaction took place in Cleveland, Ohio/USA in 1941 [1]. Recently there is a new trend as so-called small scale applications of LNG become popular. This means that smaller liquefaction capacities, smaller tankers and vessels distributing LNG as well as smaller storage and regasification facilities are being operated which allows a widespread employment of LNG [2] In this context, LNG is also increasingly used as an alternative fuel for ships and heavy-duty vehicles. Compared to other fuels like diesel, LNG is considered an environmentally friendly fuel as the engine emissions contain about $20 \%$ less $\mathrm{CO}_{2}, 80-90 \%$ less $\mathrm{NO}_{x}$ and almost zero PM and $\mathrm{SO}_{x}$ [3]. The interest for LNG as a green fuel is steadily rising. There are already several successful pilot projects and best practice examples. For instance, the parcel delivering company UPS is operating 112 LNG trucks and even announced to expand their LNG fleet to 800 vehicles [4]. LNG is also common as an alternative marine fuel. The total fleet fuelled with LNG encompassed more than 80 vessels in 2013 [5]. However, a chicken-and-egg problem dominates some parts of Central Europe and therefore impedes the extensive implementation of LNG in this area. The problem

Manuscript received March 17, 2015; revised June 8, 2015.

S. Pfoser, L. Simmer, and O. Schauer are with Logistikum Steyr, University of Applied Sciences Upper Austria, Wehrgrabengasse 1-3, A-4400 Steyr, Austria (e-mail: \{sarah.pfoser, laura.simmer, oliver.schauer\}@fh-steyr.at). is that the necessary infrastructure is not provided because on the one hand there is no demand for LNG signaled, and on the other hand the demand cannot be indicated due to the fact that infrastructure for the use of LNG is missing. One reason, which could leave to an even worse situation are safety concerns regarding LNG application. Although the industry has a quite good safety record [6], the anxiety that LNG might be a dangerous and explosive fuel still remains present in the minds of potential users.

Due to the cold temperature, $\mathrm{LNG}$ is a cryogenic substance which requires to be handled very carefully. LNG mainly consists of methane with amounts of other light hydrocarbons for instance propane or butane [7], [8]. Its physical properties differ from those of other fuels such as marine fuel oil, MFO (see Table I). This brings along some benefits but also entails appropriate manipulation.

TABLE I: COMPARISON OF PROPERTIES OF LNG AND OTHER FUELS [9]

\begin{tabular}{|c|c|c|c|c|}
\hline Property & "LNG & LPG & Gasoline & Fuel Oil \\
\hline Flash Point & $-306^{\circ} \mathrm{F}$ & $-156^{\circ} \mathrm{F}$ & $-50^{\circ} \mathrm{F}$ & $140^{\circ} \mathrm{F}$ \\
\hline Boiling Point & $-256^{\circ} \mathrm{F}$ & $-44^{\circ} \mathrm{F}$ & $90^{\circ} \mathrm{F}$ & $400^{\circ} \mathrm{F}$ \\
\hline $\begin{array}{l}\text { Flammability } \\
\text { Range in Air }\end{array}$ & $5-15 \%$ & $2.1-9.5 \%$ & $1.3-6 \%$ & N/A \\
\hline Stored Pressure & Atmospheric & Pressurized & Atmospheric & Atmospheric \\
\hline Toxic & No & No & Yes & Yes \\
\hline Carcinogenic & No & No & Yes & Yes \\
\hline Flammable Vapor & Yes & Yes & Yes & Yes \\
\hline Asphyxiant & Yes & Yes & Yes & Yes \\
\hline $\begin{array}{l}\text { Extreme Cold } \\
\text { Temperature }\end{array}$ & Yes & $\begin{array}{l}\text { Yes, if } \\
\text { refrigerated }\end{array}$ & No & No \\
\hline $\begin{array}{l}\text { Other Health } \\
\text { Hazards }\end{array}$ & None & None & $\begin{array}{c}\text { Eye irritant, } \\
\text { narcosis, } \\
\text { nausea, } \\
\text { others }\end{array}$ & $\begin{array}{c}\text { Eye irritant, } \\
\text { narcosis, } \\
\text { nausea, } \\
\text { others }\end{array}$ \\
\hline
\end{tabular}

LNG is odorless, colorless, non-corrosive, non-flammable as well as non-toxic. It has to be stored in isolated containers and tanks to keep the cold in as well as the heat out. Additionally it is necessary to prevent any object or material from freezing, becoming brittle or losing its functionality and strength [8]. It is important that throughout the whole LNG value chain, i.e. from well to wheel, each element is planned and controlled diligently, that dedicated safety and security systems are available and operational processes are executed unexceptionally by trained personnel [10].

\section{RESEARCH QUESTIONS AND METHODS}

As already mentioned, the specific requirements for handling LNG cautiously and properly may cause uncertainty by potential users. The trend towards small scale LNG applications implicates that also the end users of the value chain directly get into contact with this cryogenic fuel, for example truck drivers when they refuel their trucks. However, end users are usually non-professionals who do not have profound knowledge of LNG. This may cause further 
anxieties and might in the worst case be a reason, which inhibits fleet operators from switching to LNG as an alternative fuel. For this reason, the aim of this paper is to carry out a deliberate hazard analysis to assess all safety concerns regarding the use of LNG as a fuel. It will be a well-to-wheel analysis; this means that the hazards along the whole LNG value chain will be appraised. The conventional supply chain includes companies which are exploring and extracting natural gas, other companies that liquefy it and shippers which transport the LNG to large import terminals. At the import terminals, LNG is either regasified to feed it into the local gas pipelines or, like it is the case when LNG is used as an alternative fuel, it is distributed and stored in liquefied form, to supply refueling stations. This refers to the downstream part of the value chain, where the truck drivers are the end users of LNG [11].

The first research question is therefore: Which safety hazards exist along the LNG value chain? Based on the results of this analysis, qualifications and skills will be derived. These qualifications need to be possessed by personnel engaged in LNG processes to ensure that the operations are accomplished in a safe way. The second research question is therefore: Which competences must people involved in LNG activities have? The aim is to raise awareness for LNG as an alternative fuel and to take away the fear of safety problems by deliberately describing these hazards and defining competences which secure safe operations to prevent dangers. This should encourage potential users to switch to LNG.

The method used for the hazard analysis is extensive literature research and desktop research as there are already quite a number of studies and publications available dealing with the sources of danger accompanied by LNG. For the derivation of competences, the hazard analysis has been studied carefully and hence qualifications have been defined. To validate the relevance of the determined competences, empirical evidence has been gathered by evaluating 65 questionnaires completed online by companies engaged in logistics, inland navigation and related sectors. The respondents are predominantly involved in LNG activities. LNG hazards belong to their day-to-day operations and therefore they are experts in calculating LNG as a hazard. Within the questionnaire, they had to attach importance to the defined competences. The clear determination of hazards associated with LNG and competency profiles to prevent these hazards should foster the establishment of LNG applications, especially in those regions where the mentioned chicken-and-egg dilemma currently inhibits the implementation of this alternative fuel.

\section{HAZARD ANALYSIS}

Potential hazards especially for operators of LNG facilities or surrounding municipality arise from the basic properties of natural gas and the hazards of explosion or fire. Additionally, LNG entails risk through the cold temperature. The most relevant types of hazards will be explained hereafter.

\section{A. Possibility of Fire and Explosions}

The main threat that exists in terms of LNG or particularly of LNG spills is fire. However, LNG itself is not flammable, only the vapor of LNG might be flammable if there is a specific gas-air mixture which meets an ignition source, this could for example also be static electricity. The flammable limit of LNG in the air is $5-15 \%$, which is exceeded relatively quickly. When LNG spills near an ignition source, the vaporizing gas might start burning back to the LNG pool [12], [13]. This is referred to as pool fire.

In contrast to this, so-called jet fires occur when pumping during LNG loading activities or transportation processes causes pressure. A jet fire is not very likely related to LNG storage containers or tanks because LNG is not stored under pressure [14].

Vapor cloud fires or also called flash fires are similarly less likely than pool fires but not less hazardous. A vapor cloud fire emerges for instance if a large amount of LNG spills from a ship or tanker on the surface of water [15] or on land and does not ignite immediately. A vapor cloud is formed by the evaporating natural gas [12]. So, the emerging evaporating pool generates a vapor cloud that may drift some distance from the spill site propelled by wind. If such a vapor cloud meets an ignition source and ignites, the result is a flash fire [7].

Theoretically possible but highly unlikely is a vapor cloud explosion. It is a damaging overpressure that can occur when LNG vapor contains more than $15-20 \%$ of heavy gas components like propane [13]. It should be mentioned that methane is one of the least flame reactive hydrocarbons and does not detonate in open air. Therefore, an outdoor vapor cloud explosion is absolutely doubtful to happen [7].

A hazardous thermal event well known in the gas industry is BLEVE, which stands for boiling liquid expanding vapor explosion. A BLEVE is the result of a fire surrounding a container with flammable liquids which is under pressure. Consequently, the liquid gets heated and the pressure increases [16]. This will get critical if the pressure relief equipment or the pressure relief system fails completely. The resulting explosion happens when the pressure reaches the point where the vessel bursts and container pieces powered outward at a very high speed [17]. Anyhow, a BLEVE is also a highly improbable event, only two incidents related to LNG road transportation have occurred in the past. This is among other things due to different, non-uniform storage facilities, the materials used for the containers and the atmospheric pressure under which LNG gets stored [6], [7]. Still, experts do not agree if a BLEVE is a potential hazard or not [17].

\section{B. Rapid Phase Transition (RPT)}

When the phenomenon Rapid Phase Transition takes place, there is actually no combustion, therefore it is also called flameless explosion or physical explosion. RPT occurs when two liquids with a significantly different temperature and boiling point come in contact with each other. The boiling point of one liquid is far below the normal temperature of the other liquid as for example this is the case when LNG spills on water or land [6], [7], [18]. Under certain conditions only, the vaporization rate produced can be so high that a physical explosion occurs [19] and vapor is produced spontaneously and very rapidly as overpressure is generated during or following a spill of LNG. This phenomenon is highly localized within or in the immediate vicinity of the spill area [18]. No injuries on humans have been recorded from an 
LNG RPT yet but nevertheless they sound and look like explosions and equipment as well as LNG facilities have already been damaged. RPT cannot happen if a cryogenic liquid gets spilled on hard surfaces [6]. Determining factors for the occurrence of an LNG RPT are for instance the water temperature, the volume flow rate and the composition of LNG [17].

\section{Rollover}

Concerning the storage of LNG, a safety concern known as rollover has to be taken into account. This hazard refers to the spontaneous mixing of LNG layers of different qualities, i.e. compositions and densities, in a storage container or cargo tank. This might result in a rapid release of large amounts of LNG vapors. The crucial point for a rollover is the incurrence of stratification. Stratification appears if LNG is delivered from different producers with a different quality and stored in the same tank. Due to the recent trend of supplying LNG based on short-term contracts and generally due to globalization this problem is prominent [20]. This hazard is categorized as a risk for personnel at LNG import as well as export terminals. The first big incident happened in Italy in 1971. Since then, rollovers have received considerable attention. To avoid incidents of rollover, efficient measures can be taken. For example, the quality of LNG is usually examined before it is filled in a tank. Furthermore, the content of a tank can be mixed in order to prevent stratification [21].

\section{Sloshing}

Since there has been an increase in demand for LNG, the most efficient economical method to transport the substance over long distances is by means of huge LNG carriers. These carriers have large tanks with a holding capacity of about $150,000 \mathrm{~m}^{3}$. As a matter of fact, certain motions of the liquid in the tank arise due to the pitching and tossing of the sea [7], [22], [23]. The sloshing of the LNG can lead to damages of a different degree of severity inside the tank [7].

There have been several tests and experiments in terms of long-term sloshing effects, the impact of different tank capacities or varying ship sizes. Only few relevant incidents happened related to sloshing. The first so-called "phenomenon of resonance" was noticed in 1969. The ship's motions and the cargo's movement caused waves that damaged some of the tanks on board the LNG carrier. In 2006 , during a standard ship inspection in Spain, some deformations due to sloshing where found in the tanker of a LNG carrier. However, no major damages to the carriers or its crew members were recorded during the 40 year long history of LNG transportation. Intensive testing still takes place and further improvements will bring a better understanding of this type of hazard and technical progress for the future [24].

\section{E. Freeze or Cryogenic Burns}

Due to its very low temperatures, LNG causes damage if it comes in contact with human skin and effects freeze burns. This is a hazard for employees but not for the general public. Injuries can easily be prevented by using personal protective equipment, in short PPE, such as full-face shields and long gloves [7], [16]. As a matter of course, using this PPE is mandatory. In 1977 in Arzew, Algeria, a ship loading operation lead to cryogenic burns for a worker because LNG under pressure accidentally leaked near enough the person and a valve ruptured. This accident was the trigger for changes in the material of valves; current practice requires valves to be made of stainless steel and not aluminum as it was in 1977 [7]. Another cryogenic health hazard associated with LNG is the breathing of the cold vapor which causes a frosting of the lungs [16]. Furthermore, LNG is not only damaging people but also effects the structure of certain materials that do not undergo a ductile to brittle transition, DBT, such as aluminum, brass, copper or steel. This is a unique hazard of LNG; there exists no comparable risk for conventional liquid fuels. However, ships, tanks or buildings can be made of respective appropriate material and therefore this threat can be avoided [6], [16].

\section{F. Asphyxiation}

In case that LNG gets spilled over water and does not ignite, there is danger of asphyxiation. Although LNG is classified as a nontoxic substance, nearby situated persons such as crew members, ship passengers or other personnel could asphyxiate if the released LNG reaches a certain concentration where air is replaced and it comes to a deficiency of oxygen which happens mainly in enclosed spaces [25], [26]. The released LNG vapors dilute the oxygen in the breathing zone of people. It is generally assumed that it is unlikely that asphyxiation accidents happen at outdoor facilities [7].

\section{G. Earthquakes and Tsunamis}

When estimating the risk of LNG projects, the design of modern LNG facilities such as import and export terminals include the consideration of earthquakes and, as these facilities are usually located close to the coastline, the possibility of a tsunami resulting from an offshore earthquake. The frequency of an earthquake and its magnitude is depending on the global location, nearby geological faults and also on local soil conditions. Two relevant international codes for the seismic design requirements of LNG facilities exist: NFP 59A and EN 1473. These codes regulate specific procedures for earthquake design. In addition, there are design standards with similar requirements in terms of assuring safeness on Japanese LNG facilities. As Japan is one of the largest importers of LNG due to the country's insularity, there are many storage facilities and moreover, earthquakes are most likely as it is one of the most seismically active areas worldwide. However, looking at historically relevant earthquakes or subsequent tsunamis, it can be concluded that even very large ones have never caused major incidents at LNG facilities. Actually, in 1995, during a 6.8 earthquake on the Richter scale none of the existing LNG storage tanks in the Kobe area, Japan was damaged. Only in 2011 there was damage at the Great East Japan LNG facilities because of a tsunami that directly followed an earthquake. Current seismic design standards include adequate safety margins. It is important that the regulations, standards and fitness for service of the seismic design are reviewed every time a large earthquake occurs [5], [27].

\section{H. Terrorism}

Due to the high visibility of the LNG infrastructure and all its facilities it is easily identified and might therefore be a 
target to terrorist attacks. As a result of acts of terrorism for instance at terminals it could come to the release of large amounts of LNG. For this reason, this hazard must be paid attention to. Consequently there must be general enforcement of security to protect all types of facilities and public places, including LNG operations, from acts of violence. Currently neither an LNG tanker nor a land-based facility has been attacked by terrorists and modern safeguard systems already exist. However, some experts say that economically motivated terrorist attacks against offshore platforms recently increased especially in countries like Colombia, Nigeria or Indonesia. It has to be stated that this hazard does not only concern LNG facilities but basically all natural gas and oil facilities as these have been favored terror targets in past [12]. The major danger caused by terrorists is a fire, not an explosion. If for example an aircraft crashes an LNG facility due to the aircraft's fuel it will start to burn. Additionally, it could ignite the stored LNG which causes an even larger fire. Security distances of LNG facilities, emergency fire detections and other protection systems protect the general public from this type of hazard. To prevent terrorist attacks on LNG facilities or carriers there exist action plans for security breach, inspections, patrols as well as emergency communication systems and intelligence gathering [5].

\section{REQUIRED COMPETENCES TOWARDS LNG AND SAFETY}

The preceding hazard analysis provided a deliberate overview of all kinds of safety concerns that might arise along the LNG value chain. This allows drawing conclusions about specific qualifications and skills that must be met by personnel involved in LNG processes. The described types of hazards have been analyzed to derive these competences. Within the activities of the large European project "LNG Masterplan", various curricula for the training of different personnel engaged in LNG bunkering processes and related operations have been developed. These curricula also partly contain the competences described below and can be found in [28]. Hereafter, the main qualifications developed from the hazard analysis will be described.

\section{A. Definition of Competences}

First of all, it is important to have basic knowledge about the properties of $L N G$ due to the fact that these properties characterize LNG as an energy source and they are also the features which can make it hazardous. Therefore, an examination of its chemical and physical properties is a basic requirement and fundamental to understand LNG properly. Furthermore, these characteristics determine how LNG behaves. It is also necessary to differentiate its properties as a gas from its properties as a liquid and those as a vapor. Key attributes to be known are storage temperatures, critical temperatures, flashpoint, lower and upper explosion limit and auto ignition temperature of LNG as well as the composition and quality attributes of LNG.

Second, the personnel must understand the main risks accompanied with these characteristics of LNG. Employees need to know the risks bound up with a cryogenic substance. They must be able to explain the above described phenomina (Rapid Phase Transition, BLEVE, rollover, sloshing and so on), and they must also be aware of the danger associated with cloud formation when LNG comes into contact with outside air and other warm surfaces. Of course they must also keep in mind the dangers related to electrostatic electricity and ignition sources. Understanding these risks also includes interpreting the Material Data Safety Sheet of LNG.

Another important capability is to recognize dangerous situations. As the personnel is engaged in handling LNG, it must be able to describe the hazards associated with LNG, above all regarding the low temperatures. For example, as illustrated above, the cryogenic properties might affect standard steel components upon contact. Employees must also observe hazardous zones and accompanied operational limitations in those zones.

Finally, the ability to accomplish the safety and security precautions must be provided to avoid dangerous situations and react in the right way in case of a present hazard. The risks connected with LNG can be prevented by obeying international and national standards, codes plus regulations which control the use of LNG. Four layers of protection basically ensure safety in the LNG industry: Primary containment, secondary containment, control systems and safeguard systems [5], [29]. The primary containment involves storage tanks and other equipment that comes in contact with LNG and must be made of suitable materials and appropriate engineering design. The secondary containment ensures that if leaks or spills occur, in the unlikely event that the primary containment is breached, the LNG can be contained. This secondary containment is designed to ensure that LNG still is kept isolated. Control systems, operational integrity and protocols, operator knowledge as well as training and experience represent the next layer of protection and should be implemented and respected by every person dealing with LNG. Additionally, everyone has to use his appropriate personal protective equipment (PPE) in a correct way. The final layer, the safeguard system, is employed in case of an incident to minimize any release of LNG and mitigate potential adverse impacts. To achieve this level of safety protection, LNG facilities have to establish technological systems such as gas, liquid and fire detectors to rapidly identify any breach in containment and induce remote and automatic fail-safe, shut-off and control systems. Personnel must be able to test and operate these detectors and be able to execute the emergency response plans. There are also separation distances to be regarded. The staff needs the ability to mitigate LNG spills, control different kinds of LNG fires and detect gas leaks.

On the whole, a highly developed safety culture must be maintained, safe working procedures must be realized and basic first aid in case of injuries due to exposure to LNG must be performed. Awareness for the safety aspects must be in place.

\section{B. Empirical Evidence}

For determining empirical evidence for the defined competences towards the safe handling of LNG, 65 companies have completed an online questionnaire within the scope of the already mentioned project "LNG Masterplan" [30]. The aim was to elaborate if the stated qualifications and skills are considered to be relevant by practitioners. The respondents were companies operating in the sectors of logistics, inland navigation, bunkering, terminals or 
waterway authorities. The majority of the respondents is involved in LNG activities. Their task was to assess how important several competences towards LNG operations are. The importance of each competence had to be estimated twice: first for personnel at an operational level and second for the management level. There were six response options: "not at all important", "slightly important", "important", "fairly important", "very important" and "do not know". A detailed description of the whole dataset can be found in [30].

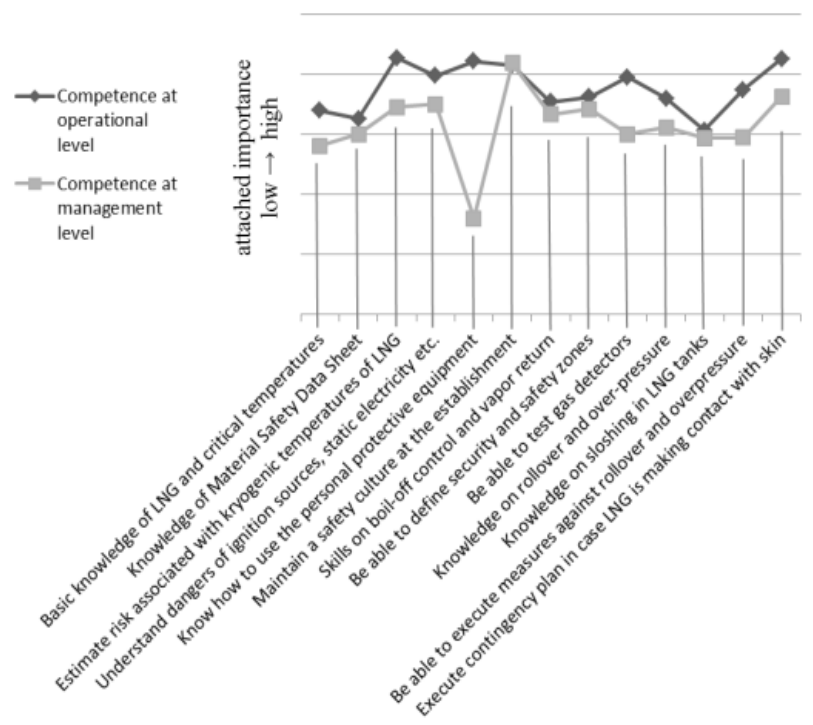

Fig. 1. Empirical evidence for defined competences.

Fig. 1 illustrates the results of the questionnaire. As it can be seen, all defined competences have on average been rated as important or fairly important. Basically it is considered that safety competences are even more important on operational level than on management level. This can especially be seen at the item "use of personal protective equipment" which is comprehensible because the management level is rarely getting into direct contact with LNG. These findings support the postulated competences needed to ensure safe LNG activities.

\section{CONCLUSION}

Generally speaking, the LNG business has had a remarkable safety record over the past decades, although LNG is a substance which must be handled with care due to its cryogenic properties. There exist more than 80 LNG fuelled ships, 23 LNG export terminals and 58 LNG import terminals worldwide; for more than 60 years LNG has been delivered safely. Relatively few incidents, injuries or deaths were caused by LNG even though more than 700 tank trucks are in service; further trucks are delivering LNG on the roads at a routine business and more than 220 huge LNG carriers and ships cross the oceans filled with the cryogenic liquid. The risks associated with LNG are appraisable and controllable. Most of the described hazards are highly unlikely and protective measures have been described for each threat.

Within the LNG Masterplan, a comprehensive list of all recorded LNG incidents and their consequences has been collected in a thorough safety study. Looking through this list it can be seen that there was one very severe accident in 1944 in Cleveland/Ohio with 128 dead and 225 injured persons. These numbers are absolutely alarming, but this incident was the only one where damage to the general public occurred. Since then, no accident with this severity happened anymore. Examining the other occurrences listed in this safety study of the LNG Masterplan, it appears that most often technical and/or human malfunction has been the cause. With regards to the types of hazards described above in III A-H, it has been recorded that most of them occurred at one time or another with more or less severe consequences. In 1971, the first recorded LNG rollover took place when unloading LNG into a storage tank with a release of about $300 \mathrm{~m}^{3}$ of LNG. Two layers of LNG with different densities and heat content were formed. This caused a pressure rise inside a $50,000 \mathrm{~m}^{3} \mathrm{LNG}$ storage tank at the terminal in Italy. The sudden mixing of two layers resulted in the release of large volumes of vapor. Within a few hours, 2,000 tons of LNG vapor discharged from the tank safety valves and vents, slightly damaging the roof of the tank but without ignition and without any consequences to human beings. In 1973 there was a rapid phase transition recorded in Essex/United Kingdom. Due to a glass breakage a small amount of the cryogenic liquid spilled onto water and it came to a RPT. Again, this incident only caused damage to the property and not to any people. In 2000, the LNG carrier USS Cole suffered from a terrorist attack in the port of Aden, Yemen. An explosive-laden boat caused a $12 \times 18 \mathrm{~m}$ gash at the galley. 17 sailors died. Finally, an incident with BLEVE has been recorded in Spain in 2002. A truck carried LNG as cargo and used Diesel as a fuel. It is believed that the truck was speeding, overturned and caught fire. The fire became larger and the LNG tank exploded. The result was a large fireball. This accident caused the driver's death and burn injuries by two persons standing 200 meters away.

There exist governmental regulations, standards and codes to regulate safety aspects concerning LNG. There are differences between the regulations in Europe, Asia and the United States. Mainly European and American standards are used worldwide and ensure a high level of security. Prospectively, existing gaps concerning certain safety regulations must still be closed and international standards need to be supported.

On the whole it can be concluded that the LNG industry is subject to similar routine hazards and safety considerations that occur in any industrial activity. Various risk mitigation systems reduce the possibility of occupational hazards and ensure the protection of surrounding communities and the natural environment. As with any industry, LNG operators must conform to all relevant national and local regulations. Beyond routine industrial hazards, the cryogenic temperature associated with LNG activities creates a number of specific safety considerations. However, unexperienced end users at the downstream part of the LNG value chain do not have to be concerned. They can protect themselves by accepting the safety requirements and using protective equipment like masks and gloves.

The present work provided a collection of competences needed to ensure that persons involved in LNG activities operate safely. Empirical evidence confirmed the relevance of these qualifications. Providing personnel with this 
knowledge and experiences can help to make each level of the LNG value chain even safer than in the past.

\section{REFERENCES}

[1] U. Fahl et al., "Possibilities of using LNG in Baden-Württemberg," Center for Energy Research Stuttgart, Stuttgart, Germany, 2009.

[2] I. Maynitskiy, "The evolution of small-scale LNG markets. The view from Gazprom export," presented at the Small Scale LNG Forum, Fleming Europe, Istanbul, Turkey 2012.

[3] S. Kumar et al., "LNG: An eco-friendly cryogenic fuel for sustainable development," Applied Energy, vol. 88, pp. 4264-4273, 2011.

[4] R. Piellisch, "Many more LNG trucks for UPS," Fleets \& Fuels Online, 2013.

[5] B. Forsman and J. Algell, "Pilot study on the use of LNG as a fuel for a high speed passenger ship from the Port of Spain ferry terminal in Trinidad and Tobago," SSPA, Göteborg, Sweden, December 2013.

[6] W. S. Wayne, "LNG bunkering issues - An overview of LNG properties and their safety implications," Argent Marine Management, Incline Village, NV, June 2013.

[7] J. Woodward and R. M. Pitblado, LNG Risk Based Safety: Modeling and Consequence Analysis, New Jersey: John Wiley \& Sons, 2010.

[8] GIIGNL, LNG Information Paper No. 1 - Basic Properties of LNG, Paris, France, 2009.

[9] M. M. Foss, "LNG safety and security," Center for Energy Economics, Austin, UT, 2006.

[10] International Organization of Oil and Gas, "Guidelines for systems and installations for supply of LNG as fuel to ships," OGP Draft 118683, London, UK, June 2013.

[11] PwC, "The economic impact of small scale LNG," Netherlands, 2013.

[12] P. W. Parfomak, "Liquefied natural gas (LNG) infrastructure security: Background and issues for congress," CRS Report for Congress, RL32073, September 2013.

[13] J. Havens, T. Spicer, H. Walker, and R. E. Martin, "LNG vapor cloud exclusion zone requirements need review," presented at 8th Topical Conference on Natural Gas Utilization, New Orleans, Louisiana, April 2008.

[14] T. Albert, "Liquefied natural gas: An overview of the LNG industry for fire marshals and emergency responders," National Association of State Fire Marshals, Washington, DC, 2005.

[15] M. K. O'Connor Process Safety Center, "LNG pool fire modeling," White Paper, Artie McFerrin Department of Chemical Engineering, Texas, September 2008.

[16] N. Siu, S. J. Herring, L. Cadwallader, W. Reece, and J. Byers, "Qualitative risk assessment for an LNG refueling station and review of relevant safety issues," Idaho National Engineering and Environmental Laboratory - U.S. Department of Energy, 1998.

[17] M. J. Murphy, N. H. Ketola, and P. K. Raj, "Clean air program from the federal transit administration: Summary assessment of the safety, health, environmental and system risks of alternative fuel," U.S. Department of Transportation, Federal Transit Agency, 1999.

[18] G. A. Melhem, S. Saraf, and H. Ozog, "LNG properties and hazards," ioMosaic Corporation, Salem, NH, 2006.

[19] P. Cleaver et al., "Rapid phase transition of LNG," in Proc. Twelth International Conference on Liquefied Natural Gas, Gas Technology Institute, Chiacgo, IL, 1998.

[20] SIGTTO, "Guidance for the prevention of rollover in LNG ships," SIGTTO London Liaison Office, London, UK, 2012.

[21] A. Bashiri and L. Fatehnejad, "Modeling and simulation of rollover in LNG storage tanks," in Proc. 23th World Gas Conference, IGU, Amsterdam, 2006.

[22] J. F. Kuo et al., "LNG tank sloshing assessment methodology - The new generation," International Journal of Offshore and Polar Engineering, vol. 19, no. 4, pp. 241-253, December 2009.
[23] D. H. Lee, M. H. Kim, S. H. Kwon, J. W. Kim, and Y. B. Lee, "A parametric and numerical study on LNG-tank sloshing loads," in Proc. the $15^{\text {th }}$ International Offshore and Polar Engineering Conference, Seoul, Korea, June 2005.

[24] T. Gavory and P. E. de Seze, "Sloshing in membrane LNG carriers and its consequences from a designer's perspective," International Society of Offshore and Polar Engineers (ISOPE), 2009.

[25] B. Forsman, "North European LNG infrastructure project: A feasibility study for an LNG filling station infrastructure and test of recommendations," SSPA, Göteborg, Sweden, November 2011.

[26] M. Hightower et al., "Guidance on risk analysis and safety implications of a large liquefied natural gas (LNG) spill over water," Sandia National Laboratories, SAND2004-6258, Albuquerque, New Mexico, December 2004.

[27] A. Acton, D. Brown, and P. Langry, "LNG incident identification Updated compilation and analysis by the international group of LNG importers," GIIGNL, Paris, France, 2013.

[28] J. M. de Groen et al., "Sub-activity 4.2 report on curricula for personnel involved in bunkering of LNG, LNG terminals, LNG fuelled vessels and logistics," Final Report of the project LNG Masterplan for Rhine-Main-Danube, STC, Rotterdam, Netherlands, July 2014.

[29] GIIGNL, "LNG information paper No. 7 - Questions \& answers," Paris, France, 2009.

[30] J. M. de Groen et al. "Sub-activity 4.2 Report on the bunkering activities questionnaire," Final Report of the project LNG Masterplan for Rhine-Main-Danube, STC, Rotterdam, Netherlands, July 2014.

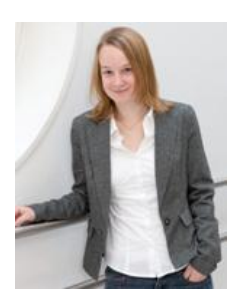

Sarah Pfoser was born in Austria, on August 30, 1989. She obtained her master's degree in management and applied economics at the Johannes Kepler University in Linz, Austria. Since 2013, she has been a research associate at the University of Applied Sciences in Upper Austria. She has work experience in project management and qualitative research activities. Her current research focuses on alternative fuels and sustainable freight transport concepts.

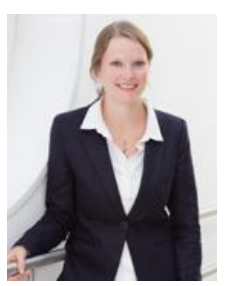

Laura Simmer was born in Austria, on January 15, 1988. She obtained her M.Sc. degree in environment and bio-resources management at the University of Natural Resources and Life Science in Vienna, Austria. She is currently a research associate at the University of Applied Sciences in Upper Austria. Her research interest focuses on sustainable transport systems.

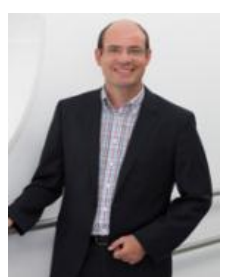

Oliver Schauer was born in Austria, on March 24, 1974. He obtained his diploma in law (Mag. Iur.) at the Faculty of Law, Johannes Kepler University in Linz in 1997. In 2001, he received his doctorate in law (Dr. iur.), graduated with distinction at the Faculty of Law, Johannes Kepler University, Linz. In 2005 he finished his executive master of business administration (MBA) at LIMAK Johannes Kepler University Business School, Linz. Mr. Schauer has work experience as a lecturer (secondary profession) at the Johannes Kepler University, Linz and at the University of Applied Sciences Upper Austria. $\mathrm{He}$ also was the head of Personnel, Legal \& Risk Management Department and member of the Executive Management at Schachinger Holding Transport \& Logistik GmbH. Since 2012 he has been a professor in mobility and transport management at the University of Applied Sciences Upper Austria. 
Renewable Energy Policy 
